\title{
Intrauterine devices and risk of uterine perforation: current perspectives
}

\author{
This article was published in the following Dove Press journal: \\ Open Access Journal of Contraception \\ 16 March 2016 \\ Number of times this article has been viewed
}

\author{
Sam Rowlands' \\ Emeka Oloto \\ David H Horwell ${ }^{3}$ \\ 'Centre of Postgraduate Medical \\ Research and Education, Faculty \\ of Health and Social Sciences, \\ Bournemouth University, Dorset, UK; \\ ${ }^{2}$ Staffordshire and Stoke on Trent \\ Partnership NHS Trust, Leicester. \\ UK; ${ }^{3}$ Spire Harpenden Hospital, \\ Harpenden, UK
}

\begin{abstract}
Uterine perforation is an uncommon complication of intrauterine device insertion, with an incidence of one in 1,000 insertions. Perforation may be complete, with the device totally in the abdominal cavity, or partial, with the device to varying degrees within the uterine wall. Some studies show a positive association between lactation and perforation, but a causal relationship has not been established. Very rarely, a device may perforate into bowel or the urinary tract. Perforated intrauterine devices can generally be removed successfully at laparoscopy.
\end{abstract}

Keywords: uterine perforation, intrauterine device, intrauterine system

\section{Introduction}

The aim of this review is to raise awareness of the circumstances in which perforation of the uterus by intrauterine devices (IUDs) can occur, the consequences of such perforations, and approaches to the management of suspected or actual perforation.

IUDs for contraception were first introduced by Richter ${ }^{1}$ in 1909 and were further developed and deployed by Gräfenberg ${ }^{2}$ from 1929; there was then a resurgence with the modern era beginning in 1959 when flexible plastic IUDs were introduced. ${ }^{3}$ Over the years, there have been many design modifications to improve effectiveness, acceptability, and safety. ${ }^{3}$ IUDs are a highly effective form of long-acting reversible contraception.

Use of intrauterine contraception worldwide is extensive: $13.9 \%$ of the world's 1.16 billion women aged $15-49$, married or in a union, are using this method. ${ }^{4}$ Uptake of intrauterine contraception in China is even higher at $40.6 \%$ of their 269 million women aged 15-49.

Perforation of the uterus with IUDs was first described in the 1930s. ${ }^{5,6}$ Initially, there was denial that this could happen at the time of insertion, and it was postulated that devices were always forced through the uterine wall by uterine contractions. ${ }^{7}$ Consensus opinion is now that the most common mechanism is that the device is forced into or through the uterine wall at the time of insertion. Other terms such as "the wandering IUD", the misplaced/displaced or missing IUD, ectopic IUD, migration, mislocation, transmigration, or translocation are therefore somewhat misleading. Less commonly, an IUD may penetrate into but remain within the myometrium; this is termed partial perforation. ${ }^{8}$ It appears that uterine contractions can sometimes force such a device through the uterine wall.

Although uterine perforation is a potentially serious complication of intrauterine contraceptive use, it is uncommon and it can often be asymptomatic.
Sam Rowlands

Centre of Postgraduate Medical Research and Education, Faculty of Health and Social Sciences, Bournemouth University, R506 Royal London House, Christchurch Road, Bournemouth BHI 3LT, UK

Tel +44 I 202962782

Email srowlands@bournemouth.ac.uk 
Some cases are not identified until months or years after insertion. ${ }^{9-11}$ In one series, the longest interval that had elapsed between insertion and diagnosis was 43 years. ${ }^{12}$ It is therefore important to put uterine perforation into context. It very rarely leads to harmful sequelae, and it does not detract from the overall excellent safety record of IUDs. ${ }^{3}$

\section{Literature search}

A formal Medline search using the search terms uterine perforation, displac*, migrat*, perforat*, penetrat*, and translocat* together with intrauterine devices or intrauterine devices copper or intrauterine devices medicated gave 629 English language results. Of these, 347 were found to be relevant. A similar search in EMBASE produced 418 relevant articles out of a total of 914 . Further references were found within these articles.

\section{Methodological considerations}

Perforation of the uterus with an IUD is an uncommon phenomenon. Of the perforations that do occur, most do not cause long-term harm, although women are generally advised to go through a surgical removal procedure that has some risks. However, a significant harm associated with perforation may be the loss of the IUD's contraceptive effect, resulting in unplanned, and often unwanted, pregnancy. Sometimes a perforation leads to trauma to internal structures; such cases are thought to be very rare.

Quantification of the incidence of perforation from large cohort studies has been done and is likely to be precise. How many of these perforations go on to become more complicated is not known at all. Assessing the strength of risk factors for perforation is difficult. For instance, the definition of breast-feeding is imprecise, as many women reduce the amount they feed gradually over time and so it is not an "all or nothing" variable. Although one study with no association at all was found, there may be other negative studies that editors did not see fit to publish. There may also be smaller negative studies without the statistical power to give a valid result. There is therefore a potential risk of publication bias.

Apart from the data on incidence from cohort studies, much of the literature on this subject consists of isolated case reports; there are also some relatively small case series. This is the lowest quality of evidence in the hierarchy of evidence apart from "expert opinion". ${ }^{13}$ This state of affairs means that when presenting the data there will inevitably be selection bias. Clinicians like to report unusual cases. In general, this bias will exaggerate the risks associated with uterine perforation.
The authors have not cited all case reports that were found in the literature. We have selected citations that describe each facet of the subject well, choosing for preference papers that have a case series rather than an individual case report, and papers that have reasonable literature reviews.

As this review is of necessity based mainly on findings from cohort studies, small series, and case reports, it cannot by its nature be a systematic review. However, the authors have attempted to collate current knowledge and opinion on this topic.

\section{Terminology}

Initially modern devices were "inert", made entirely of metal or plastic. In the late $1960 \mathrm{~s}$, copper was added to plastic devices to increase their efficacy; a "frameless" copper-only device, GyneFix $^{\circledR}$ (Contrel, Ghent, Belgium), also became available in 1996. Hormone-releasing devices were developed to improve IUD efficacy and to reduce certain complications such as bleeding and pain. Copper-containing and hormone-releasing types of device are sometimes termed as "medicated" IUDs.

The abbreviation used for intrauterine devices known as a whole and for a conventional (nonhormone releasing) intrauterine device is IUD. Many types of IUD have been available over the years, latterly all with added copper. Several types of progestin-releasing IUD are now available; these will be referred to collectively as the IUS, the abbreviation for intrauterine system. Examples of past and currently available IUDs are shown in Figure 1.

\section{Mechanism of perforation}

Esposito et al $^{14}$ postulated that two mechanisms of uterine perforation exist.

1. Immediate traumatic perforation

2. Later "secondary" perforation caused by gradual erosion through the myometrium

Confirmation of the latter mechanism has been achieved by serial computed tomography (CT) scans performed for nongynecologic purposes. ${ }^{15}$

In the early days of IUDs, insertion instruments were rigid and so perforation was more likely as a consequence. ${ }^{16}$ An early version of the Birnberg bow had a perforation rate of one in 200 because of the rigidity of its inserter. ${ }^{17,18}$ With the Progestasert device, there was documented evidence of a reduction in perforation rate when the inserter was made more flexible and a uterine sound included in the package. ${ }^{19}$ Nowadays, insertion tubes are made so that they are more flexible, but not so soft that they buckle easily. Other risk factors are use of a push-out insertion technique, or lack of 

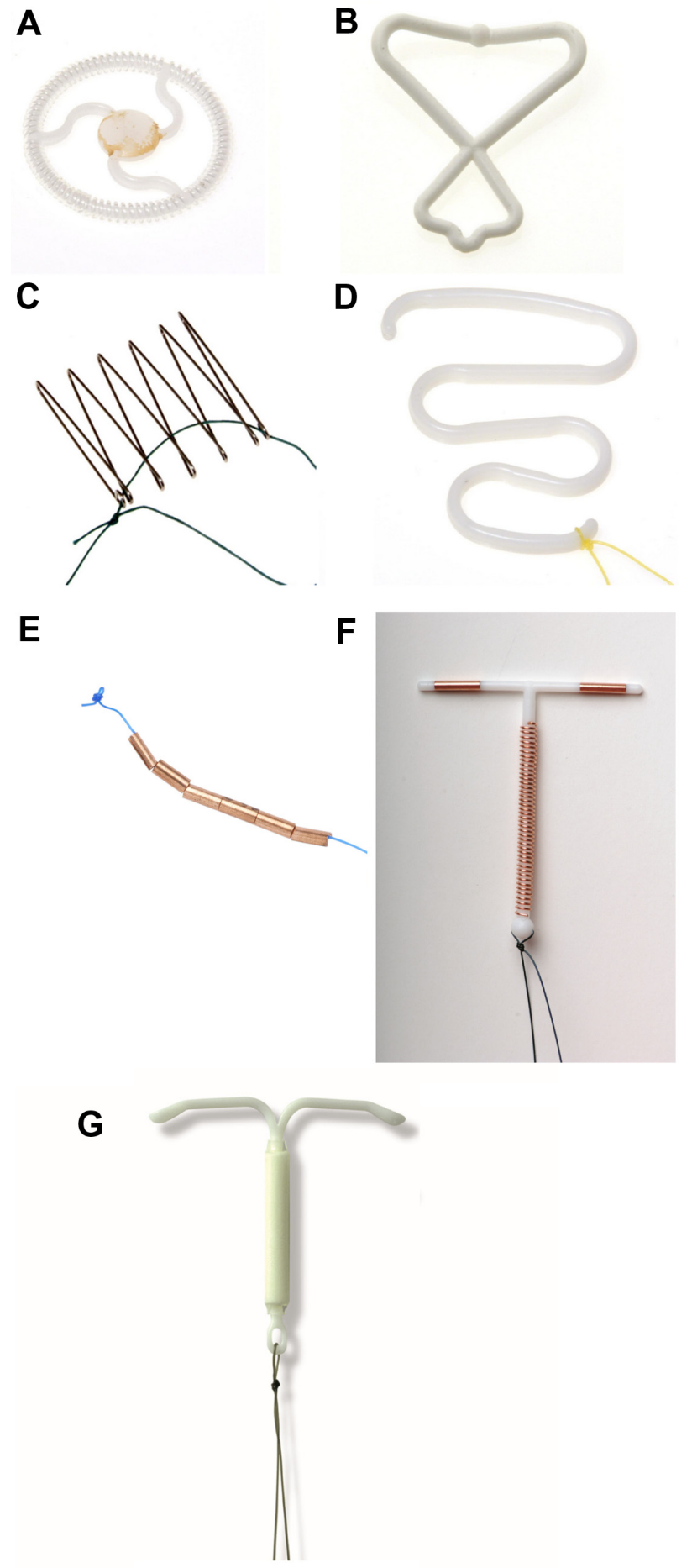

Figure I Types of device.

Notes: (A) Ota Ring, (B) Birnberg Bow, (C) Majzlin Spring, (D) Lippes Loop, (E) GyneFix ${ }^{\circledast}$, (F) copper-bearing device: CuTT380 slimline, and (G) Levonorgestrel intrauterine system: Mirena ${ }^{\circledR}$. Types (A-D) all obsolete. Images (A-D) courtesy of the Museum of Contraception and Abortion, Vienna (www.muvs.org). Images (E-G) courtesy of Durbin PLC, South Harrow, Middlesex, UK (www.durbin.co.uk).

an insertion tube, as was the case with the Dalkon Shield (Dalkon Corporation, Defiance, OH, USA).

Perforation can also happen with a uterine sound. Traditionally, metal sounds were used to measure the uterine cavity length. Plastic sounds are almost certainly safer as they are less rigid. Perforation of the uterus may occur when the uterus is being sounded, or a false track may be created which is then followed by the IUD.

The forces required to insert an IUD increase linearly with increasing inserter tube diameter. ${ }^{20}$ The force required to insert an IUD is generally $1.5-6.5 \mathrm{~N}$. The forces generated physiologically within the uterus have been estimated to be theoretically as high as $50 \mathrm{~N}$, sufficient to produce uterine perforation. This would explain the so-called "secondary" perforation as a consequence of embedment of a device. Except in cases of lactation or uterine atrophy (eg, due to long-term use of injectable progestins), it is thought that the forces required to cause perforation are higher than the forces needed to carry out insertion of an IUD.

\section{Classification}

Uterine perforation by IUDs was analyzed in detail by Zakin et $\mathrm{al}^{8}$ in a now-classic paper. The authors based their analysis on the 356 cases that they found in the literature in 1981. They described complete perforation, which is the device passing through all uterine layers - endometrium, myometrium, and serosa - to lie freely in the peritoneal cavity or enveloped by omentum or traveling into other rarer locations. In a minority of cases, the IUD penetrates only into the myometrium, which they termed partial perforation. Zakin et $\mathrm{al}^{8}$ made the important points that missing removal threads do not necessarily imply that a device is incorrectly located and conversely that the threads may be visible when a device has perforated.

Three anatomical compartments are considered, disregarding the endometrium and serosa. These are as follows:

1. Uterine cavity

2. Myometrium

3. Peritoneal cavity

\section{Partial perforation}

The partially perforated device may be present in one, two, or all three anatomical compartments (Figure 2). A device with a type A perforation that is mainly situated in the uterine cavity (A1) will be easier to remove than one in which the IUD is mainly in the myometrium (A2). Indeed, removal of the latter can be difficult or even hazardous. Following a type $B$ perforation the IUD lies entirely within the myometrium so that it cannot be seen either at hysteroscopy or laparoscopy. In a type $\mathrm{C}$ perforation the device has protruded into the peritoneal cavity but is still fixed in the myometrium. In a type $\mathrm{D}$ perforation, portions of the device are situated in all three compartments and a detailed assessment will be needed to 


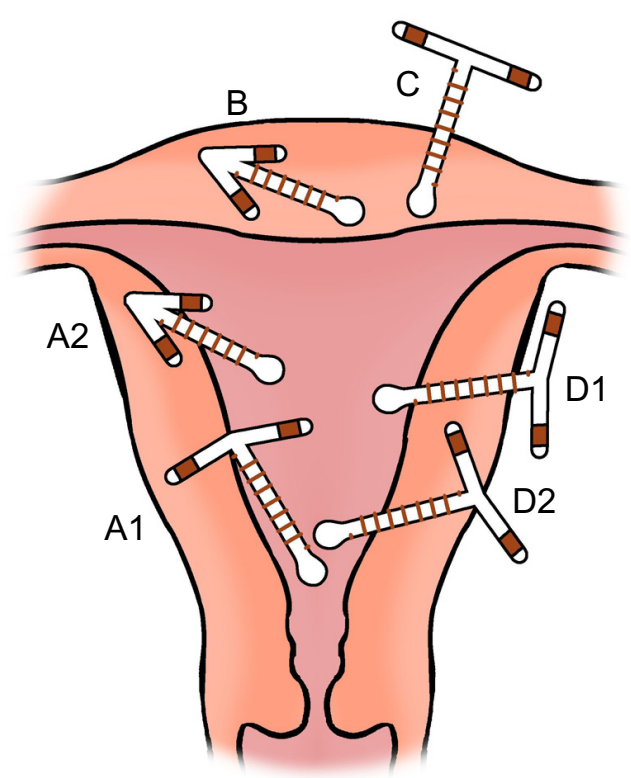

Figure 2 Classification of partially perforated devices.

Notes: Type A: IUD present in uterine cavity and myometrium; Type B: IUD present entirely in myometrium; Type C: IUD present in myometrium and peritoneal cavity; Type D: IUD present in all three compartments. A copper-T device is depicted: any device can perforate the uterus. The size of the IUDs relative to the uterus has been slightly reduced for illustrative purposes.

Abbreviation: IUD, intrauterine device.

plan the mode of removal; D2 will be more complex to remove laparoscopically than D1.

A partial perforation may remain as such or it may convert into a complete perforation within a matter of days. This latter conversion is almost certainly due to uterine contractions pushing the device through the myometrium, the force needed depending on the shape of the device.

In a very unusual case, an IUD moved during pregnancy from a location in the lower uterine segment at 16 weeks' gestation to the posterior fundal myometrium at the time of a 20 -week miscarriage, to erosion into small bowel, found at laparoscopic sterilization 6 weeks later. ${ }^{21}$

\section{Complete perforation}

With a complete perforation of the uterus, the device may remain near the uterus or it may move within the abdominal cavity. Zakin et $\mathrm{al}^{8}$ found that the most common location for a completely perforated IUD is the pouch of Douglas. In nearly half of complete perforations, the device is located in the omentum, either loosely or adherent to it; in the latter case it may be so densely adherent that a portion of omentum needs to be excised in order to remove the device. The threads of a completely perforated device will generally not be visible at the cervix by the time of follow-up.

\section{Embedment}

Here, a device impinges on the endometrium with a force sufficient to cause pressure necrosis of underlying tissue and penetration into the superficial layers of the myometrium. ${ }^{22}$ This phenomenon was seen in the past in women using the Majzlin spring device. When removal of an embedded device is attempted, trauma to tissues may occur. Great care is needed in cases of embedment if marked pain is caused at attempted removal. In one case, this caused a tear which resulted in a 2-liter hemorrhage. ${ }^{23}$

\section{Incidence of perforation}

Perforation of the uterus is uncommon: estimates in larger studies range from 0.4 to 1.6 per 1,000 insertions. ${ }^{9,19}$ A nationwide prospective cohort study from New Zealand over a 10-year period found 28 perforations among 17,469 insertions of the Multiload ${ }^{\circledR}$ Cu375 IUD (Merck and Co., Inc., Whitehouse Station, NJ, USA), giving an incidence of 1.6 per 1,000 insertions. ${ }^{9} \mathrm{~A} 3$-year study by the same group found three perforations in 3,519 IUS insertions, giving an incidence of 0.9 per $1,000 .{ }^{24}$ Both these studies represent "real-life" results, which give a truer picture than clinical trials, especially when IUDs are being inserted by generalists. A Turkish hospital-based study of the T-380A IUD followed up women at 1 year and found an incidence of 2.2 per 1,000 insertions. ${ }^{25}$ Other studies that could not be so certain of the denominator have found lower rates; for instance a Finnish study calculated an incidence of 0.4 per 1,000 sold devices. ${ }^{26}$ One study found a higher perforation rate in women using an IUD for the first time compared to women who had used the method previously. ${ }^{27}$

The long-standing debate about whether or not lactation is a risk factor for perforation with IUD insertion is described in the "Effect of insertion after pregnancy or during lactation" section.

Rates of perforation with any IUD may in part be influenced by the experience or the maintenance of skill of the operator. This was first mooted in a report from Singapore, in which more perforations were seen in insertions by junior doctors or general practitioners than by experienced gynecologists. ${ }^{7}$ In a large prospective cohort study of a copper IUD, doctors who had inserted fewer than ten IUDs during the 10 -year study period ( $73 \%$ of the sample) had significantly higher perforation rates than those who had inserted between ten and 99. ${ }^{9}$ The European Active 
Surveillance (EURAS) study showed a higher perforation rate in insertions performed by clinicians who inserted fewer than 50 devices per year compared to those inserting 50 or more per year. ${ }^{27}$

Although spontaneous reporting to national databases gives no feel for incidence due to the lack of a denominator, it is interesting to note that since its launch in 1996, there have been 114 reports of uterine perforation with the levonorgestrel IUS in the UK and 23 reports of such devices becoming embedded in the uterus, cervix, or other local tissues. ${ }^{28}$

\section{Different device types}

Perforation occurs with all device types, whether IUDs or IUSs (Figure 1). This includes frameless copper devices such as the GyneFix ${ }^{\circledR} \cdot{ }^{29-31}$ Perforation with the sharp tip of the GyneFix ${ }^{\circledR}$ stylet is potentially dangerous. A Cochrane review concluded that it is not known if the perforation rate for framed devices differs from frameless devices; one perforation was noted with GyneFix ${ }^{\circledR}$ in the studies reviewed (approximately 3,000 insertions) compared to none with the TCu380 framed device. ${ }^{32}$ The possibility has been raised that the GyneFix ${ }^{\circledR}$ anchoring knot may sometimes be located on the serosal surface of the uterus at the end of the insertion procedure, ${ }^{33}$ either because the thickness of the fundal myometrium may in some cases be less than originally thought when GyneFix ${ }^{\circledR}$ was designed or because of thinning associated with long-term injectable progestin use. ${ }^{33,34}$

The type of framed device does not appear to be an influencing factor in perforation rates. ${ }^{32} \mathrm{~A}$ large European cohort study (EURAS) found no clinically important differences in perforation rates between copper IUDs and the Mirena ${ }^{\circledR}$ IUS (Bayer Schering Pharma, Turku, Finland) ${ }^{27}$. There is no significant difference in perforation rates between Levosert ${ }^{{ }^{R}}$ (Actavis, Hafnarfjörður, Iceland) and Mirena ${ }^{\circledR}$ IUSs. ${ }^{35}$ Early experience with newer low-dose levonorgestrel IUSs in clinical trials has found a low crude incidence for complete or partial perforation $(0 \%-0.03 \%))^{36,37}$

\section{Risk factors for uterine perforation}

Possible risk factors for perforation are listed below. However, the associations are either weak or inconsistent, so causality has not been demonstrated.

- Insertion by less experienced clinicians ${ }^{7,9,27}$

- Lactation: see the "Effect of insertion after pregnancy or during lactation" section

- Postpartum insertion ( $<6$ months since delivery $)^{25,27}$
- Lower parity ${ }^{25}$

- Higher number of previous abortions ${ }^{25}$

Age of the woman, history of dilation and curettage, and history of cesarean section have been found not to be associated with risk of uterine perforation. ${ }^{25,27}$

\section{Effect of insertion after pregnancy or during lactation}

The myometrium is softer when in the pregnant state and for a time afterwards, so is more vulnerable to being torn or punctured during instrumentation. Involution starts immediately after delivery and is rapid during the first week; by 2 weeks postpartum the uterus is contained within the pelvis; by about 4 weeks it is close to normal size. During full breast-feeding, estrogen levels are very low and the uterus is consequently small. As noted by Chi et al, ${ }^{38}$ IUD insertion is less painful in lactating women; this may be due to increased levels of $\beta$-endorphins. ${ }^{39}$ Perforation during insertion at this time may be associated with little pain and may therefore be less likely to be noticed at the time of its occurrence.

Perforation in the postpartum period is generally rare. A Singaporean study in the 1960 s (in which 2,487 of 8,977 insertions were postplacental, ie, within 48 hours of delivery) recorded 93 perforations with the Lippes loop, ${ }^{7}$ where the perforation risk was perhaps high due both to its mode of release from its insertion tube and to its linear form if it did not conform to the shape of the uterine cavity. A later Californian study of insertions between 4 and 8 weeks postpartum showed a zero perforation rate with copper-7s and copper-Ts. ${ }^{40}$ In a Turkish study of copper T380A insertions, no perforations were observed at up to 6 weeks postpartum, but there were some when insertions were done after 6 weeks. ${ }^{41}$

The possibility that women who are lactating are more susceptible to perforation of the uterus when an IUD is inserted was first raised in $1966 .^{16,42}$ This phenomenon was first investigated in a USA case-control study. ${ }^{43}$ This study showed a tenfold higher risk of perforation in women who were lactating at the time of IUD insertion compared to women with at least one live birth who were not lactating.

However, subsequent studies did not confirm this finding. A multicenter 6-month follow-up study of 1,149 women who underwent copper-T 380A IUD insertion found no perforations in any of the women, breast-feeding or not breast-feeding. ${ }^{38}$

Analysis of 50 perforations reported to a Swedish insurance scheme register found that 27 of the women 
(54\%) were breast-feeding at the time of insertion. ${ }^{39}$ A multicenter pharmacovigilance study found that $42 \%$ of women with IUS perforations were breast-feeding at the time of diagnosis. ${ }^{10}$ Also, in the EURAS study, a sixfold increase in risk of perforation associated with breastfeeding was found. ${ }^{27}$

It is therefore not possible to give a definitive answer as to whether breast-feeding increases the risk of perforation. Current professional guidance gives no restriction on eligibility for IUD insertion after 4 weeks from delivery (postpartum), regardless of whether or not a woman is breast-feeding. ${ }^{44}$ For IUD insertion between 48 hours and 4 weeks postpartum, WHOMEC ${ }^{45}$ and $\mathrm{UKMEC}^{46}$ assign category 3 (risks generally outweigh advantages), but USMEC ${ }^{47}$ assigns category 2 (advantages generally outweigh risks). In June 2015, the UK Medicines and Healthcare Products Regulatory Agency (MHRA) reviewed risk factors for perforation in light of the EURAS study results ${ }^{27}$ and concluded that the benefits of intrauterine contraception strongly outweigh the risks, including in those who are lactating or who have recently given birth. ${ }^{48}$

A systematic review of studies of surgical abortion and of miscarriage treated surgically, followed immediately by IUD insertion, showed perforation rates of one per 1,000 and 0.9 per 1,000 , respectively. ${ }^{49}$

\section{Perforation sites}

Perforation typically occurs into the uterorectal pouch (pouch of Douglas, cul-de-sac) with an anteverted uterus (Figure $3 \mathrm{~A}$ ) or the vesicouterine pouch if it is retroverted ${ }^{8}$ (Figure 3B). Flexion of the uterus is also a factor. In one series, ultrasound examination of women with perforated IUDs showed a significant number with an acute angle of flexion of the uterine body in relation to the cervix. ${ }^{12}$ Perfo-

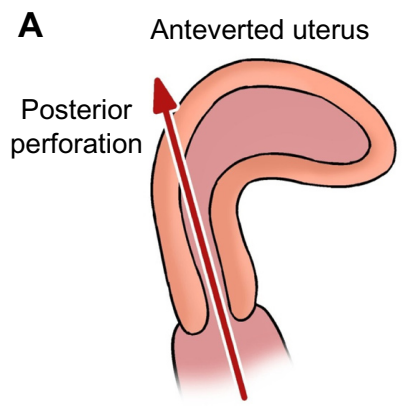

B Retroverted uterus

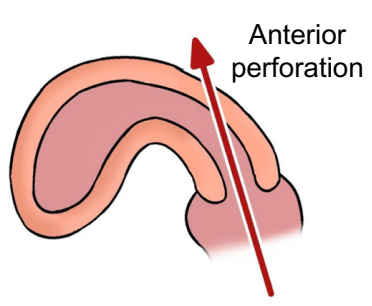

Arrow indicates direction of travel of device

Figure 3 Diagrams showing direction of perforation in different uterine positions. Notes: (A) Posterior perforation in an anteverted uterus; (B) Anterior perforation in a retroverted uterus. ration can also occur through the fundus, particularly if the uterus is in an axial orientation. It has also been reported to occur into the uterosacral ligament, ${ }^{50}$ broad ligament, ${ }^{50-52}$ fallopian tube, ${ }^{53}$ and ovary. ${ }^{54}$ There is a report of IUD threads coming through the posterior fornix; after failed localization at laparoscopy, the IUD was removed by colpotomy. ${ }^{55} \mathrm{In}$ one case, an IUD was found within an ovarian carcinoma. ${ }^{56}$ Very rare sites have been described such as the anterior abdominal wall. ${ }^{57-59}$ There is one recorded case of sciatica after a posterior perforation. ${ }^{60}$

Most commonly the perforated device is found free in the peritoneal cavity. However, ultimately, it usually becomes attached to an organ, the bowel, the mesentery, or most commonly the omentum. ${ }^{61}$ Rarely, adhesion formation stimulated by a perforated device has resulted in intestinal obstruction. ${ }^{62}$

Perforation of the cervix is very rare and usually asymptomatic. It is postulated that some degree of malposition of the device later results in force exerted by the vertical stem with slow, repetitive uterine contractions which gradually propel the device through the cervical tissues ${ }^{8,63}$ Fortunately, removal can be relatively easy, usually by freeing the device initially by pushing it up toward the uterine cavity. There are reported cases of cervical perforation by the threads only, ${ }^{64}$ which were found running in a fistulous tract along the ectocervix. One author postulated that this may have been preceded by trauma to the cervix from a tenaculum. However, this phenomenon can occur at sites other than where the tenaculum has been placed. ${ }^{65}$

\section{Perforation into bowel}

Perforation of large and small bowel, appendix, and rectum have been described. ${ }^{66-68}$ Removal sometimes has to involve resection of a segment of bowel. There are occasional reports of successful removal of an IUD per rectum by proctoscopy or colonoscopy. ${ }^{69,70}$ There is one case report of a perforated frameless IUD which apparently disappeared from the body, presumably via the intestine. ${ }^{71}$

Perforation with a modern T-shaped IUD has been known to cause partial intestinal obstruction. In a Danish case report, a perforation next to the sigmoid colon presented 5 years after insertion with thickening of the bowel wall causing acute abdominal pain. ${ }^{72}$ Zakin et $\mathrm{l}^{8}$ described the "stopper effect" whereby a device that had perforated into bowel leaves a defect in the bowel wall on removal through which bowel contents can pass, with resultant peritonitis. An exceedingly rare complication is fistula formation between different 
sections of bowel. ${ }^{73,74}$ A case of intestinal gangrene has also been reported. ${ }^{75}$

\section{Perforation into the urinary tract}

There are more than 70 cases of perforation involving the urinary tract reported in the literature. ${ }^{76}$ Perforation through to the bladder or ureter is an uncommon but regularly reported complication of IUD insertion. In some cases, there is urinary calculus formation around the device. ${ }^{77}$ In one case report, the IUD was mainly situated in the urethra. ${ }^{78}$ There is one report of menouria (vesical menstruation) due to a vesicouterine fistula, ${ }^{79}$ and another report of formation of a colovesical fistula. ${ }^{80}$ There are three reported cases of retroperitoneal location of a perforated IUD with fibrosis around the right pelvic ureter leading to right hydronephrosis. ${ }^{81,82}$ IUDs and associated bladder calculi can be removed cystoscopically. ${ }^{77,78}$

\section{Localization of devices that have perforated}

The first warning sign, and the most common reason for investigation, of possible uterine perforation is the finding of missing or lost IUD/IUS threads. The bedrock of diagnosis of perforation and localization of a perforated device is ultrasound scanning. Localization of devices is more precise using transvaginal scanning than with transabdominal scanning. Ultrasound scanning is a better modality for identifying devices that are intrauterine rather than extrauterine. IUDs are easier to identify than IUSs on an ultrasound scan (Figure 4) as ultrasound imaging of the original (52 mg) levonorgestrel IUS (Mirena ${ }^{\circledR}$ ) depends principally on the finding of an acoustic "shadow" rather than on visualizing the device itself. The inclusion of a silver ring at the junction between the vertical stem and side arms of the smaller dimension $13.5 \mathrm{mg}$ IUS (Jaydess $^{\circledR}$ and Skyla ${ }^{\circledR}$; Bayer AG, Leverkusen, Germany) permits easier visualization of the device by ultrasound scanning and distinguishes it from Mirena ${ }^{\circledR}$ on ultrasound scan and from Mirena ${ }^{\circledR}$ and other devices on X-ray.

In one series, ultrasound scanning failed to show the perforated device in more than half of cases. ${ }^{12}$ In this series, IUSs were more likely than IUDs to be missed. A perforated IUS that was ultimately shown on X-ray and CT scan had been missed by ultrasound scan alone. ${ }^{83}$ In another series, there was a noticeable discrepancy between the location of IUSs indicated by ultrasound imaging and subsequent actual location at surgery. ${ }^{84}$ Ultrasound can easily miss IUDs located in the upper abdomen. ${ }^{84}$ Both IUDs and IUSs are radiopaque,
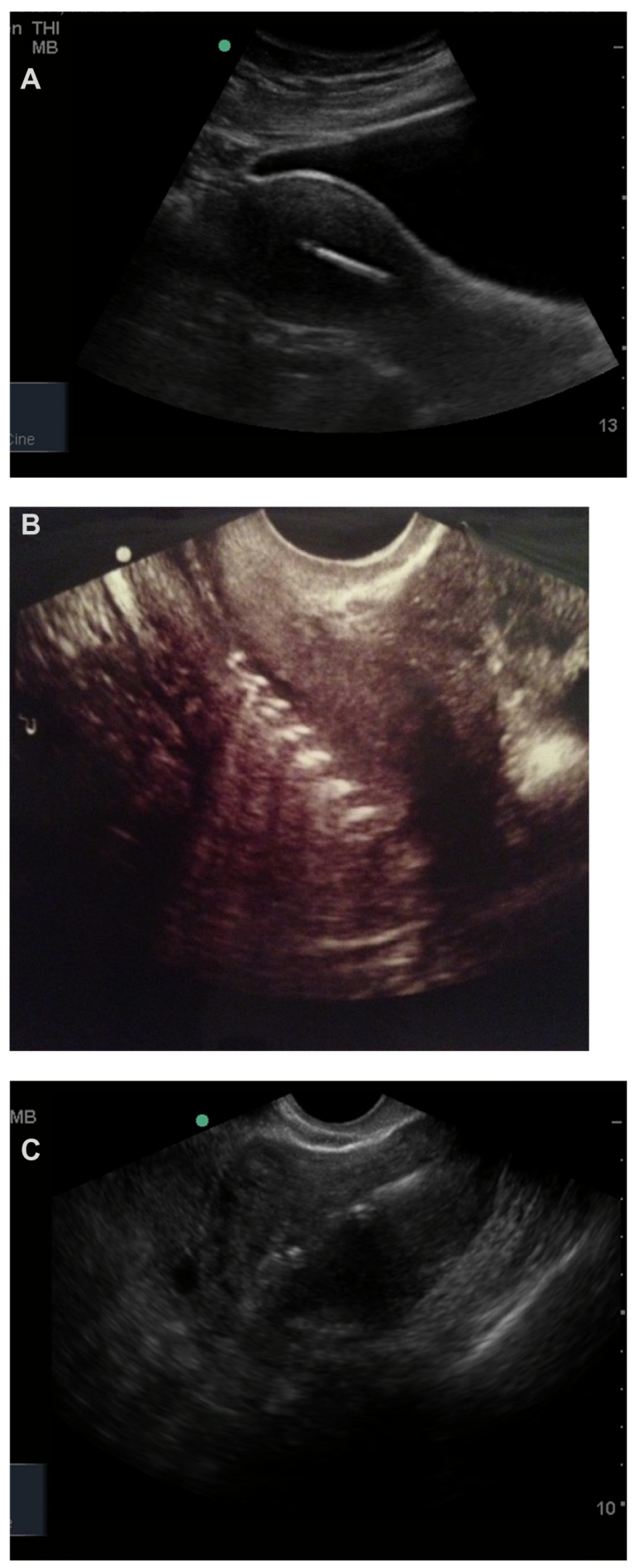

Figure 4 Ultrasound scan images of intrauterine IUDs and an IUS.

Notes: (A) Sagittal view of framed IUD, (B) frameless IUD, and (C) sagittal view of IUS showing triangular acoustic shadow of device. Pictures courtesy of Emeka Oloto. Abbreviations: IUD, intrauterine device; IUS, intrauterine system.

so if they are in the abdominal cavity they will always be visible on a whole-abdominal and pelvic X-ray view, but the precise location may still be uncertain (Figure 5); a CT 

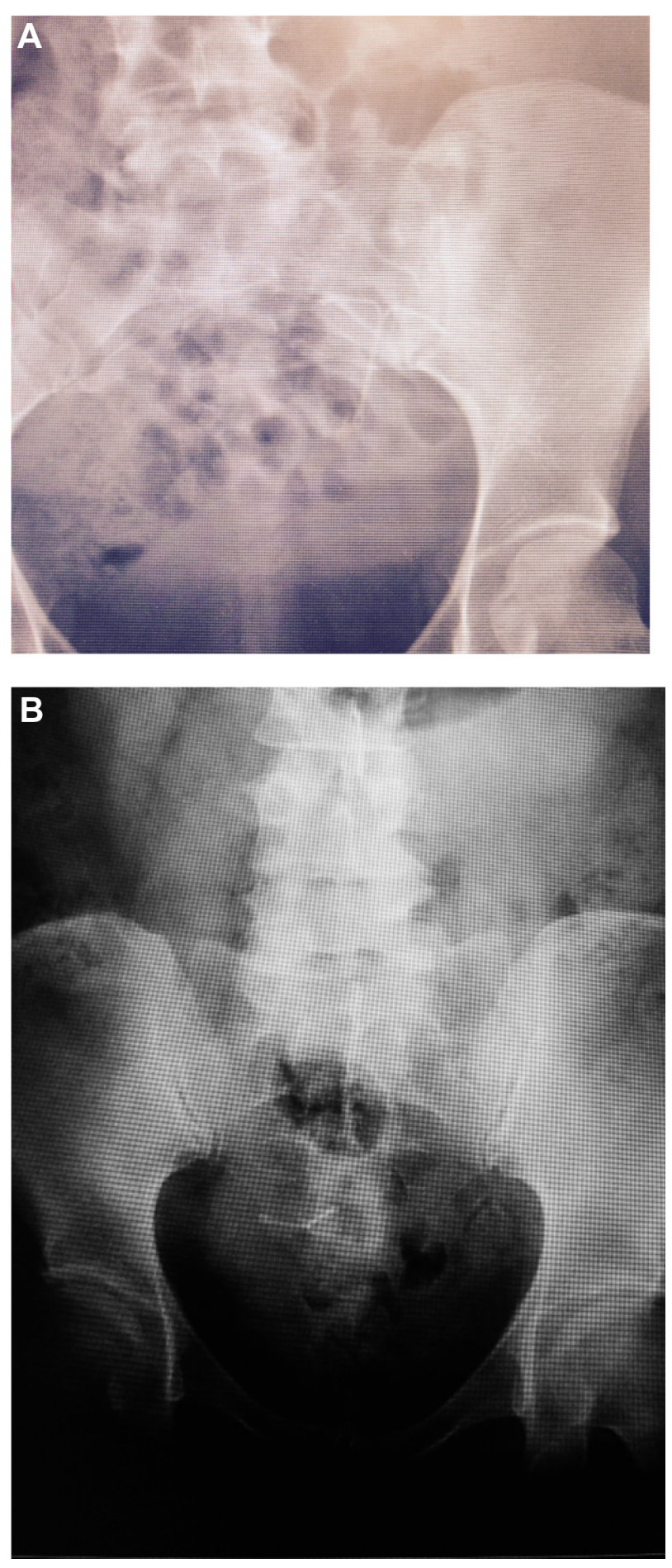

Figure $5 \times$-ray images of extrauterine IUD and IUS.

Notes: (A) Nova-T 380 IUD and (B) Mirena ${ }^{\circledR}$ IUS. Pictures courtesy of Emeka Oloto. Abbreviations: IUD, intrauterine device; IUS, intrauterine system.

scan or magnetic resonance imaging will be able to localize devices of any type more accurately. ${ }^{85}$

\section{Clinical features}

A scenario that has occurred regularly, particularly in the more distant past, is that a clinician makes a presumption that "lost" threads are due to an IUD having been expelled, leading to long delays in diagnosis if an ultrasound scan, and if necessary an X-ray, is not performed to confirm the absence of the device. Sometimes another device is inserted so that both an intrauterine and an extrauterine device are present. Rarely, a perforation is not detected by ultrasound scanning and a second perforation occurs in the same individual. ${ }^{86,87}$

Assessment of the size and position of the uterus is essential before insertion of an IUD. Use of a uterine sound and traction with a tenaculum was suggested in $1966^{16}$ and has become part of routine practice. This is particularly important where there is sharp ante- or retroversion of the uterus, acute ante- or retroflexion, or a severe mismatch of flexion and version ${ }^{12}$ (Figure 3); if these angulations are not straightened with traction using a tenaculum then perforation is probably more likely. ${ }^{88}$ Setting the flange on the introducer accurately to the uterine cavity length as measured with the sound is also important.

Uterine perforation can occur with the sound, with the device itself, or with both. If the sound or inserter pass further than one would normally expect (over 10-11 cm) and if no resistance is felt, then this should be regarded as suspicious and the instrument or device immediately withdrawn from the uterus and the procedure abandoned. If perforation is suspected following insertion of the device, an ultrasound scan may be carried out immediately if the facilities and skills are available, or arranged via an imaging department.

In around $90 \%$ of cases, perforation is not recognized at the time of IUD insertion. ${ }^{9,10}$ The threads are generally still emerging from the cervical os at the end of the procedure, even with a complete perforation. Sometimes perforation is suspected between the time of insertion and follow-up, due to persistent symptoms, mainly mild lower abdominal pain. One of the main purposes of follow-up about 6 weeks after insertion is to exclude expulsion and perforation. In most cases of perforation the threads are not visible at 6 weeks. However, not all women attend for this follow-up examination. In a few cases in which the IUD is located in the pouch of Douglas, the device can be palpated on vaginal or rectal examination. ${ }^{8}$

Many instances of perforation are diagnosed later than the follow-up examination, often because of the occurrence of a pregnancy, which may be ectopic. ${ }^{89}$ Other indicators of perforation are "lost" threads and persistent lower abdominal pain. In the 10-year New Zealand cohort study, over half of perforations were diagnosed more than 1 year after insertion. ${ }^{9}$ 
It should be borne in mind that when a perforated IUS lies close to the uterus, the woman may still experience amenorrhea from local progestin release ${ }^{90}$ the IUS may also have an adequate "remote" contraceptive effect. ${ }^{91}$ A perforated IUS has been reported as a rare cause of secondary infertility. ${ }^{92,93}$ In one case of IUS perforation, plasma levonorgestrel levels were higher from intraperitoneal release than are generally found from intrauterine release. ${ }^{94}$ In the Finnish study, women with perforations were less likely to become pregnant if their perforated device was an IUS rather than an IUD. ${ }^{11}$ However, a case report described a pregnancy occurring with a perforated IUS well within the expected 5-year IUS life span. It was removed from the omentum at cesarean section. ${ }^{95}$

When the bowel is perforated, a triad of symptoms has been described: abdominal pain, fever, and intermittent diarrhea. ${ }^{66}$ Rectal bleeding is also possible. ${ }^{96}$ Occasionally, bowel perforation is asymptomatic with discovery as an incidental finding, for instance at hysterectomy. ${ }^{97}$ When the urinary tract is perforated, symptoms may include dysuria, frequency, suprapubic pain, hematuria, and recurrent urinary tract infections. In one case, a perforated device was missed at hysterectomy and found subsequently in the right lower quadrant, 35 years after insertion and 14 years after the hysterectomy. ${ }^{98}$ In another case, an IUS was found in the abdomen despite the patient having had a vaginal hysterectomy and admissions to hospital on account of abdominal pain. ${ }^{83}$ In the single reported case of right-sided sciatica, an IUD was resting on the lumbosacral plexus; it was postulated that the left side is protected by the sigmoid colon. ${ }^{60}$

\section{Prevention of uterine perforation}

Actions that can help to reduce the risk of uterine perforation associated with insertion of IUDs include:

- Avoidance of insertion or taking extra care (with special consent) from 48 hours to 4 weeks postpartum, especially if the woman is breast-feeding

- Use of a plastic rather than a metal sound

- Use of a suitable tenaculum and applying appropriate traction to it

- Provision of less rigid introducers by device manufacturers

- Accurate setting of the flange on the introducer according to the sounding distance and the specific instructions for the device

- A pull-back, rather than a push-out, release mechanism for the device

- Skilled insertion training for clinicians

- Insertion by experienced clinicians
There is no evidence that use of ultrasound control during the routine insertion of IUDs reduces the risk of perforation occurring. However, complex insertions (eg, after failed insertion elsewhere as a result of acute uterine ante- or retroversion or in cases of coexisting fibroids) are carried out under ultrasound guidance in many specialist centers, which will help to minimize the risk of uterine perforation. Ultrasound is also a very useful tool in verifying the location of an IUD/IUS after insertion, especially if there is concern about possible perforation.

\section{Removal of devices that have perforated}

It is conventional clinical practice to remove all devices that have completely perforated the uterine wall. Originally, this was considered vital ${ }^{99}$ as older, now obsolete, devices were "closed" (examples are Gräfenberg ring, Ota ring, Incon ring, Hall-Stone ring, Antigon and Birnberg bow - Figure 1) and a loop of bowel could pass through the device with resultant intestinal obstruction. ${ }^{100-103}$ Ring-shaped IUDs have continued to be used in China until recent years.

There is no such risk with newer, mainly T-shaped, devices (Figure 1). Many of these devices remain in the abdomen, for periods of years in some cases, without doing any harm before they are discovered. Some authorities have suggested that removal of a modern IUD is not warranted and that the risks of laparoscopy or even laparotomy are not justifiable when a woman with a perforated device is asymptomatic. ${ }^{104}$ In one case report, a 62-year old woman who had a Lippes loop in her abdomen for 42 years was followed up without recourse to surgery. ${ }^{105}$ Another reason for conservative management would be a woman with complex medical problems who is deemed unfit for surgery. ${ }^{106}$

There is, however, the question as to whether the components of IUDs (plastic frame and copper) or IUSs (plastic frame, progestin, silicone matrix and sleeve, and silver in the case of Jaydess ${ }^{\circledR} /$ Skyla $^{\circledR}$ ) induce peritoneal adhesions. A study on rabbits found that polyethylene foreign bodies elicited a peritoneal reaction with adhesion formation in most animals after 2 weeks. ${ }^{107}$ Several human studies have shown only local and delicate peritoneal adhesion formation; bands of adhesions that could cause bowel obstruction did not develop. ${ }^{104,108-110}$ An Israeli study showed no difference in the peritoneal reaction between IUDs and the IUS, ${ }^{110}$ but two other studies found that adhesion formation was more common with IUDs than the IUS. ${ }^{11,12}$ Adoni and Ben Chetrit ${ }^{104}$ were of the opinion that adhesions form during a limited period only; once formed, the authors suggested that they do 
not develop further. However, in one series, adhesions were more common when the interval from insertion to surgical intervention was greater than 8 months. ${ }^{12}$ If they form, adhesions are localized to the IUD/IUS site and prevent the device from moving further. ${ }^{109}$

The precise surgical details of removal of IUDs from the abdomen are outside the scope of this article. The first laparoscopic removal of an IUD took place in $1969 .{ }^{111}$ Laparoscopic removals have been successfully performed in pregnancy. ${ }^{112}$ Perforated IUSs have been purposely left in situ during pregnancy ${ }^{113}$ or mistakenly thought to be intrauterine ${ }^{95}$ and then removed at cesarean section.

Minimally-invasive laparoscopic removal is to be preferred, but when the removal is more complicated open laparotomy may be safer. In a 2012 systematic review of laparoscopies carried out for removal of perforated IUDs, $64 \%$ were successful and $35 \%$ needed to be converted to laparotomy. ${ }^{114}$ The case series in that review were reported between 1972 and 2002, and the scope of laparoscopic surgery has certainly progressed in recent years. It could therefore be argued that a woman whose perforated IUD cannot be removed at initial laparoscopy should be referred to a surgeon with special skills in minimal access surgery, who may be more likely to remove a device successfully and safely than a general gynecologist. Occasionally "discretion is the better part of valor" and laparoscopy or laparotomy is abandoned when retrieval is unsuccessful in cases where the device has become densely adherent to, or buried in, vital structures. It should be noted that surgery to remove an IUD may itself cause adhesion formation. ${ }^{109}$ Laparoscopic removal is not feasible in type $\mathrm{A}$ and $\mathrm{B}$ perforations. ${ }^{115}$ However, type A perforations may well be amenable to removal of the device at hysteroscopy.

In certain cases, early laparoscopy is not the preferred approach. In a retrospective series of 95 cases of perforation, two devices were removed at cesarean section and one at postpartum sterilization. ${ }^{116}$ Nitke et $\mathrm{al}^{84}$ noted that in several of their cases IUSs were located at a higher level in the abdomen at laparoscopy than had been indicated by the diagnostic erect X-ray. They postulated that IUSs attach to omentum which then shifts from pelvis to upper abdomen when the patient is in the Trendelenburg position for laparoscopy. This may also explain the more precise localization by CT scanning, during which the patient is supine. Some surgeons use X-ray imaging when the patient is positioned for surgery.

Healing of the myometrium after perforation is rapid. Often at laparoscopy a few days or weeks after IUD insertion and perforation, no scar is visible on the uterus to show the exit point. ${ }^{117}$ In the Kho and Chamsy ${ }^{12}$ series, the perforation site was identifiable in only one-third of cases. Zakin et $\mathrm{al}^{8}$ concluded that scars would disappear by 2 months after perforation. This is, however, not invariably true and sometimes a scar does persist long-term. ${ }^{118}$

\section{Medicolegal aspects}

Perforation of the uterus is a recognized complication of IUD insertion. Provided that preinsertion counseling and assessment have been carried out, with provision of written information, and the procedure is carried out using a safe technique and the patient then followed up with full documentation in the medical records, clinicians should not be vulnerable to litigation. ${ }^{119}$ Perforation is a risk each time IUD insertion is carried out in the same individual; risks should be explained at every procedure, not just the first. ${ }^{120}$

Consent for IUD insertion does not need to be in written form for nonanesthetized women, but a brief explanation of perforation along with the other complications is needed in order to obtain valid consent, including the information that the one in 1,000 risk of perforation is uncommon. This level of risk can be presented on a risk scale to make it easier to comprehend. ${ }^{121}$

\section{Conclusion}

While being an uncommon phenomenon, uterine perforation with an IUD is an important risk that must be explained to patients, prevented if possible by taking all steps to insert devices safely, and diagnosed and managed appropriately. Most cases are due to traumatic perforation that occurs at the time of insertion. However, "secondary" perforation can also occur by gradual erosion. A partial perforation may convert into a complete perforation.

Perforation occurs in one in 1,000 IUD or IUS insertions and occurs with all types of devices. The evidence on perforation and lactation is conflicting: although some studies show a positive association, others do not and so a causal relationship has not been established. Most perforations are uncomplicated, with the device lying in a quiescent state in the abdomen. However, rarely other organs can be affected, either by direct trauma at the time of insertion or by subsequent erosion. Both the bowel and the urinary tract lie in close proximity to the uterus and can be affected.

Most cases are "silent" and not recognized at the time of insertion. IUSs are quite commonly missed when abdominal ultrasound is the only imaging modality used. Transvaginal 
ultrasound scanning by the clinician searching for a "missing" device is usually the first line of investigation, but there is still much to be said for requesting a plain X-ray of abdomen and pelvis if the device is not located immediately by ultrasound scan. When perforation is diagnosed, most devices can be and should be removed. This can most often be achieved by laparoscopy; sometimes laparotomy may be needed.

IUDs are remarkably simple, safe and cost-effective, longacting contraceptives. Overall, this review demonstrates the low morbidity associated with their use, even when uterine perforation occurs.

\section{Acknowledgment}

We thank the staff at the Library, Royal Bournemouth Hospital Education Centre, for conducting the literature searches and for providing references.

\section{Disclosure}

The authors have received fees for consultancy and provision of training from the manufacturers of intrauterine devices. The authors report no other conflicts of interest in this work.

\section{References}

1. Richter R. Ein Mittel zur Verhütung der Konzeption [A means of preventing conception]. Deutsch Med Wochenschr. 1909;35:1525. German.

2. Gräfenberg E. Die intrauterine methode der konzeptionverhütung. In: Haire N, editor. Proceedings of the Third World League for Sexual Reform Congress, London 1929. London, UK: Kegan Paul, Trench, Turner and Company; 1929:166-175.

3. Sivin IB. State-of-the-art on non-hormonal methods of contraception: III. Intrauterine devices. Eur J Contracept Reprod Health Care. 2010;15:96-112.

4. United Nations Department of Economic and Social Affairs. World contraceptive patterns 2013. New York, NY: United Nations Department of Economic and Social Affairs; 2015. Available from: http:/ www.un.org/en/development/desa/population/publications/family/contraceptive-wallchart-2013.shtml. Accessed December 16, 2015.

5. Murphy MC. Migration of a Gräfenberg ring. Lancet. 1933;2: 1369-1370.

6. Andrews CJ. Migrating Gräfenberg contraception ring. JAMA. 1936; 107:279.

7. Ratnam SS, Tow SH. Translocation of the loop. In: Zatuchni GI, editor. Post-partum Family Planning: A Report on the International Program. New York, NY: McGraw-Hill; 1970:371-384.

8. Zakin D, Stern WZ, Rosenblatt R. Complete and partial perforation and embedding following insertion of intrauterine devices. I. Classification, complications, mechanism, incidence, and missing string. Obstet Gynecol Surv. 1981;36:335-353.

9. Harrison-Woolrych M, Ashton J, Coulter D. Uterine perforation on intrauterine device insertion: is the incidence higher than previously reported? Contraception. 2003;67:53-56.

10. van Grootheest K, Sachs B, Harrison-Woolrych M, Caduff-Janosa P, van Puijenbroek E. Uterine perforation with levonorgestrel-releasing intrauterine device. Drug Saf. 2011;34:83-88.
11. Kaislasuo J, Suhonen S, Gissler M, Lähteenmäki P, Heikinheimo O. Uterine perforation caused by intrauterine devices: clinical course and treatment. Hum Reprod. 2013;28:1546-1551.

12. Kho KA, Chamsy DJ. Perforated intraperitoneal intrauterine contraceptive devices: diagnosis, management and clinical outcomes. J Minim Invasive Gynecol. 2014;21:596-601.

13. CEBM. Levels of evidence (March 2009). Oxford, UK: Centre for Evidence-based Medicine; 2009. Available from: http://www.cebm.net/ oxford-centre-evidence-based-medicine-levels-evidence-march-2009/. Accessed September 2, 2015.

14. Esposito JM, Zarou DM, Zarou GS. A Dalkon shield imbedded in a myoma: case report of an unusual displacement of an intrauterine device. Am J Obstet Gynecol. 1973;117:578-581.

15. Ferguson CA, Costescu D, Jamieson MA, Jong L. Transmural migration and perforation of a levonorgestrel intrauterine system: a case report and review of the literature. Contraception. 2016;93:81-86.

16. Ledger WJ, Willson R. Intrauterine contraceptive devices: the recognition and management of uterine perforations. Obstet Gynecol. 1966;28:806-811.

17. Hall RE. A comparative evaluation of intrauterine contraceptive devices. Am J Obstet Gynecol. 1966;94:65-77.

18. Tietze C. Contraception with intrauterine devices 1959-1966. Am J Obstet Gynecol. 1966;96:1043-1054.

19. WHO Scientific Group. Mechanism of Action, Safety and Efficacy of Intrauterine Devices. Technical Report Series 753. Geneva, Switzerland: World Health Organization; 1987.

20. Goldstuck ND, Wildemeersch D. Role of uterine forces in intrauterine device embedment, perforation, and expulsion. Int J Women's Health. 2014;6:735-744.

21. Glass T, Baker T, Kauffman RP. Migration of an intrauterine contraceptive device during the course of a pregnancy: a case report. J Minim Invasive Gynecol. 2009;16:81-83.

22. Tatum HJ. Clinical aspects of intrauterine contraception: circumspection. Fertil Steril. 1977;28:3.

23. Goldman JA, Feldberg D, Dicker D. Massive hemoperitoneum due to IUD. Eur J Obstet Gynecol Reprod Biol. 1983;14:239-240.

24. Zhou L, Harrison-Woolrych M, Coulter DM. Use of the New Zealand Intensive Medicines Monitoring Programme to study the levonorgestrelreleasing intrauterine device (Mirena). Pharmacoepidemiol Drug Saf. 2003;12:371-377.

25. Caliskan E, Özturk N, Dilbaz BÖ, Dilbaz S. Analysis of risk factors associated with uterine perforation by intrauterine devices. Eur $J$ Contracept Reprod Health Care. 2003;8:150-155.

26. Kaislasuo J, Suhonen S, Gissler M, Lähteenmäki P, Heikinheimo O. Intrauterine contraception: incidence and factors associated with uterine perforation - a population-based study. Hum Reprod. 2012;27:2658-2663.

27. Heinemann K, Reed S, Moehner S, Minh TD. Risk of uterine perforation with levonorgestrel-releasing and copper intrauterine devices in the European Active Surveillance Study on Intrauterine Devices. Contraception. 2015;91:274-279.

28. Drug Analysis Print for levonorgestrel. London, UK: Medicines and Healthcare Regulatory Products Agency; 2015. Available from: http:// www.mhra.gov.uk/home/groups/public/documents/sentineldocuments/ dap_4168594933298485.pdf. Acessed September 2, 2015.

29. Gandhi JD, Whitmore J, Iskander MN. Uterine perforation by GyneFix frameless IUD: two case reports. J Fam Plann Reprod Health Care. 2001;27:153-154.

30. Aust TR, Kirwan JN, Herod JJ, McVicker JT. Perforation with the GyneFix intrauterine implant: is there a common factor? J Fam Plann Reprod Health Care. 2003;29:155-156.

31. Sajjad Y, Selvan G, Kirwan JM, Kingsland CR. GyneFix frameless IUD: cause of bowel resection. Eur J Contracept Reprod Health Care. 2006;11:241-242.

32. O'Brien PA, Marfleet C. Frameless versus classical intrauterine device for contraception. Cochrane Database Syst Rev. 2005;25(1): CD003282. 
33. Wildemeersch D. Further information and recommendations to prevent perforation with the frameless GyneFix IUD. J Fam Plann Reprod Health Care. 2001;27:241.

34. Vekemans M, Verougstraete A. Late uterine perforation with an anchored IUD, the GyneFix: a case report. Contraception. 1999;60:55-56.

35. Clinical Effectiveness Unit. Levosert. New Product Review. London, UK: Faculty of Sexual and Reproductive Healthcare; 2015. Available from: http://www.fsrh.org/pdfs/LevosertNewProductReview.pdf. Accessed September 28, 2015.

36. Gemzell-Danielsson K, Schellschmidt I, Apter D. A randomized, phase II study describing the efficacy, bleeding profile, and safety of two low-dose levonorgestrel-releasing intrauterine contraceptive systems and Mirena. Fertil Steril. 2012;97:616-622.

37. Nelson A, Apter D, Hauck B, Schmelter T, Rybowski S, Rosen K. Two low-dose levonorgestrel intrauterine contraceptive systems: a randomized controlled trial. Obstet Gynecol. 2013;122:1205-1213.

38. Chi IC, Potts M, Wilkens LR, Champion CB. Performance of the copper T-380A intrauterine device in breastfeeding women. Contraception. 1989;39:603-618.

39. Andersson K, Ryde-Blomqvist E, Lindell K, Odlind V, Milsom I. Perforations with intrauterine devices. Contraception. 1998;57: 251-255.

40. Mishell DR, Roy S. Copper intrauterine contraceptive device event rates following insertion 4 to 8 weeks post partum. Am J Obstet Gynecol. 1982;143:29-35.

41. Eroglu K, Akkuzu G, Vural G, et al. Comparison of efficacy and complications of IUD insertion in immediate postplacental/early postpartum period with interval period: 1 year follow-up. Contraception. 2006; 74:376-381.

42. Macfarlan SM. Perforation of the postpartum uterus with an intrauterine contraceptive device. Am J Obstet Gynecol. 1966;94:283-284.

43. Heartwell SF, Schlesselman S. Risk of uterine perforation among users of intrauterine devices. Obstet Gynecol. 1983;61:31-36.

44. Clinical Effectiveness Unit. Intrauterine Contraception. 3rd ed. London, UK: Faculty of Sexual and Reproductive Healthcare; 2015.

45. Medical eligibility for contraceptive use. 5 th ed. Geneva, Switzerland: World Health Organization; 2015. Available from: http://www.who.int/ reproductivehealth/publications/family_planning/Ex-Summ-MEC-5/ en/. Accessed June 12, 2015.

46. Faculty of Sexual and Reproductive Healthcare. UK Medical Eligibility Criteria for Contraceptive Use. 2nd ed. London, UK: Faculty of Sexual and Reproductive Healthcare; 2009.

47. Center for Disease Control and Prevention. US Medical Eligibility Criteria for Contraceptive Use, 2010. 4th ed. Atlanta, GA: Department of Health and Human Services, Center for Disease Control and Prevention; 2010.

48. Intrauterine contraception: uterine perforation - updated information on risk factors Drug Safety Update June 2015. London, UK: Medicines and Healthcare Products Regulatory Agency; 2015. Available from: https:// www.gov.uk/government/uploads/system/uploads/attachment_data/ file/438800/Drug_Safety_Update_-_June_2015_pdf.pdf. Accessed September 2, 2015.

49. Stanwood NL, Grimes DA, Schulz KF. Insertion of an intrauterine contraceptive device after induced or spontaneous abortion: a review of the evidence. BJOG. 2001;108:1168-1173.

50. Adiyeke M, Sanci M, Karaca I, Gökçü M, Töz E, Öcal E. Surgical management of intrauterine devices migrated towards intra-abdominal structures: 20-year experience of a tertiary center. Clin Exp Obstet Gynecol. 2015;42:358-360.

51. Mallik MK. Lippes loop in the broad ligament (report of a case of extraperitoneal migration of the loop). J Obstet Gynaecol India. 1968;18:336-337.

52. Cederqvist LL, Sarry ZI, Zervoudakis IA. Translocation of the Dalkon Shield into the broad ligament. Obstet Gynecol. 1975;46:239-242.

53. Sindos M, Pisal N, Setchell M, Singer A. Tubal migration: a rare complication of an intrauterine contraceptive device leading to formation of a hydrosalpinx. Am J Obstet Gynecol. 2003;188:1109-1110.
54. Verma U, Verma N. Ovarian embedding of a transmigrated intrauterine device: a case report and literature review. Arch Gynecol Obstet. 2009;280:275-278.

55. Nigam A, Biswas R, Mishra A. Misplaced intrauterine contraceptive device: an enigma. Open Access J Contracept. 2011;2:1-3.

56. Koo HR, Oh YT, Kim YT, Kim SW, Kang JH, Kim KW. Intrauterine device found in an ovarian carcinoma. J Comput Assist Tomogr. 2008;32:69-71.

57. Borkotoky RK, Mampilli KJ. Translocation of intrauterine contraceptive device. J Indian Med Assoc. 1976;67:147-149.

58. Ansari MM, Harris SH, Haleem S, Fareed R, Khan MF. Foreign body granuloma in the anterior abdominal wall mimicking an acute appendicular lump and induced by a translocated copper-T intrauterine contraceptive device: a case report. J Med Case Rep. 2009;3:7007.

59. Chell KI, Lipscomb GH. Abdominal wall abscess presenting 35 years after insertion of an intrauterine contraceptive device. Obstet Gynecol. 2010;115:458-459.

60. Elmer RM. Sciatica caused by an intrauterine device after silent uterine perforation. J Bone Joint Surg Am. 1978;60:265-266.

61. Sengül Ö, Dilbaz B, Kavak D, Dede S, Yerebasmaz N, Altinbas S. Surgical management of extrauterine mislocated intrauterine contraceptive devices and related risks. J Obstet Gynaecol. 2014;34:70-73.

62. Loveless A, Dhari A, Kilpatrick CC. Perforated levonorgestrel-releasing intrauterine system resulting in small bowel obstruction: a case report. J Reprod Med. 2014;59:611-613.

63. Savardekar LS, Shah RS, Vandana W. Asymptomatic cervical perforation by intrauterine copper bearing contraceptive device: two unusual cases. Eur J Obstet Gynecol Reprod Biol. 2005;120:236-237.

64. Gbolade BA. Perforation of the cervix by the threads of a levonorgestrelreleasing intrauterine system: a case report. JWomens Health (Larchmt). 2010;19:2277-2279.

65. Gönenç I, Zeynep E, Vural T, Aka N. Cervical perforation by the strings of a levonorgestrel releasing-intrauterine system: a case report. Eur $J$ Contracept Reprod Health Care. 2013;18:415-418.

66. Key TC, Kreutner AK. Gastrointestinal complications of modern intrauterine devices. Obstet Gynecol. 1980;55:239-244.

67. Chen CP, Hsu TC, Wang W. Ileal penetration by a Multiload-Cu 375 intrauterine contraceptive device. Contraception. 1998;58:295-304.

68. Singhai SR, Marwah DS, Paul A, Singhai SK. Missed intrauterine device: a rare indication for appendicectomy - case report with review of literature. East Cent Afr J Surg. 2010;15:156-158.

69. Assarian AQ, Raja MA. Colonoscopic retrieval of a lost intrauterine contraceptive device: a case report and review of articles. Eur J Contracept Reprod Health Care. 2005;10:261-265.

70. Eichengreen C, Landwehr H, Goldthwaite L, Tocce K. Rectal perforation with an intrauterine device: a case report. Contraception. 2015;91:261-263.

71. Reuter S, Krishnamurthy S. Intra-uterine implant (GyneFix) lost via intestinal route? J Fam Plann Reprod Health Care. 2001;27: 159-160.

72. Grønlund B, Blaabjerg J. Serious intestinal complication five years after insertion of Nova-T. Contraception. 1991;44:517-521.

73. Abbasoglu O, Karakayali H, Akyürek M, Cebi Y. Uterine perforation and ileosigmoid fistula caused by an intrauterine contraceptive device (case report). Eur J Surg. 1994;160:189-190.

74. Pirwany IR, Boddy K. Colocolic fistula caused by a previously inserted intrauterine device (case report). Contraception. 1997;56: 337-339.

75. Barranco CJ. IUD gangrene of small intestine. Am J Surg. 1978; 135:717.

76. Rowlands S. Lost IUD penetrating bladder wall. J Fam Plann Reprod Health Care. 2010;36:255.

77. Nouira Y, Rakrouki S, Gargouri M, Fitouri Z, Horchani A. Intravesical migration of an intrauterine contraceptive device complicated by bladder stone: a report of six cases. Int Urogynecol J Pelvic Floor Dysfunct. 2007;18:575-578. 
78. Ko PC, Lin YH, Lo TS. Intrauterine contraceptive device migration to the lower urinary tract: report of 2 cases. J Minim Invasive Gynecol. 2011;18:668-670.

79. Schwartzwald D, Mooppan UM, Tancer ML, Gomez-Leon G, Kim H. Vesicouterine fistula with menouria: a complication from an intrauterine device. J Urol. 1986;136:1066-1067.

80. Sinha PK, Shaw M, Sarkar K, Pathak H, Ghosal P, Sarkar KK. A mystery of a lost and forgotten Copper-T: a case report. Indian J Urol. 2015;31(5):Supplement.

81. El-Hefnawy AS, El-Nahas AR, Osman Y, Bazeed MA. Urinary complications of migrated intrauterine contraceptive device. Int Urogynecol J Pelvic Floor Dysfunct. 2008;19:241-245.

82. Malik T, Khan S. An unusual cause of hydronephroureter. J Coll Physicians Surg Pak. 2014;24:766-767.

83. Pappa A, Shambhu S, Phillips K, Guthrie K. A levonorgestrel-releasing intauterine system embedded in the omentum in a woman with abdominal pain: a case report. J Med Case Rep. 2009;3:9301.

84. Nitke S, Rabinerson D, Dekel A, Sheiner E, Kaplan B, Hackmon R. Lost levonorgestrel IUD: diagnosis and therapy. Contraception. 2004;69:289-293.

85. Peri N, Graham D, Levine D. Imaging of intrauterine contraceptive devices. J Ultrasound Med. 2007;26:1389-1401.

86. Özdemir H, Mahmutyazicioglu K, Tanriverdi A, Gündogdu S, SavranlarA, Özer T. Migration of an intrauterine contraceptive device to the ovary. J Clin Ultrasound. 2004;32:91-94.

87. Blanas K, Theodora M, Hassanaien M. Incidental discovery of two levonorgestrel-releasing intrauterine systems misplaced in the peritoneal cavity. Eur J Contracept Reprod Health Care. 2010;15:441-444.

88. Bromham DR. Intrauterine contraceptive devices - a reappraisal. Br Med Bull. 1993;49:100-123.

89. Kwong FN, Rai H, Mayne C. Ectopic pregnancy with a translocated Mirena intrauterine system. J Fam Plann Reprod Health Care. 2002;28:95-96.

90. Bobrow C, Cooling H, Bisson D. Amenorrhoea despite displaced levonorgestrel intra-uterine system. J Fam Plann Reprod Health Care. 2000;26:105-106

91. Kalu E, Thonet R. Oligomenorrhoea and contraception despite extrauterine location of the levonorgestrel intrauterine system: a case report. J Fam Plann Reprod Health Care. 2005;31:163-164.

92. Botros G, Haddad N. Fertility and endocrine effects of intra-abdominally misplaced intrauterine system for more than 2 years: a case report. Hum Fertil (Camb). 2009;12:119-121.

93. Doris N, Shabib G, Corbett S, Leader A, Black A. Does an intraabdominally placed LNG-IUS have an adverse effect on fertility? a case report. Contraception. 2014;89:63-66.

94. Haimov-Kochman R, Amsalem H, Adoni A, Lavy Y, Spitz IM. Management of a perforated levonorgestrel-medicated intrauterine device - a pharmacokinetic study: case report. Hum Reprod. 2003;18:1231-1233.

95. Budiman H, Kümper C, Mylonas I, Thaler CJ, Friese K, Weissenbacher ER. Pregnancy in a patient with a displaced levonorgestrel-releasing intrauterine system: a case report. Arch Gynecol Obstet. 2007;276:263-264.

96. Kim TH, Lee HH, Chung SH, Jeon DS. Hematochezia caused by intrauterine device perforation. Contraception. 2015;91:430.

97. Disu S, Boret A. Asymptomatic ileal perforation of an intrauterine device. Arch Gynecol Obstet. 2004;269:230-231.

98. Fortunato MA. The long lost IUD. WV Med J. 2007;103:22-23.

99. Hall RE. A reappraisal of intrauterine contraceptive devices. Prompted by the delayed discovery of uterine perforation. Am J Obstet Gynecol. 1967;99:808-813.
100. Price CW. An unusual case of intestinal obstruction. Med J Aust. 1955;42:106-107.

101. Esposito JM. Perforation of the uterus, secondary to insertion of IUCD Obstet Gynecol. 1966;28:799-805.

102. de Villiers EH, Rosenstein PF. Intestinal obstruction following perforation of the uterus with an intrauterine contraceptive device. Am J Obstet Gynecol. 1966;96:592.

103. Haspels AA. Small bowel obstruction due to perforation by a closed ring type intrauterine device (Antigon). J Obstet Gynaecol Br Commonw. 1969;76:178.

104. Adoni A, Ben Chetrit A. The management of intrauterine devices following uterine perforation. Contraception. 1991;43:77-81.

105. Sezer SD, Odabasi AR, Kücük M, Yüksel H. Lost intrauterine contraceptive device inserted 42 years before: a case report. Clin Exp Obstet Gynecol. 2011;38:90-93.

106. Majd HS, El Hamamy E, Chandrasakar R, Ismail L. Migration of levonorgestrel IUS in a patient with complex medical problems: what should be done? Arch Gynecol Obstet. 2009;279:385-386.

107. Echenberg R, Ledger WJ. Peritoneal response to polyethylene foreign bodies. Obstet Gynecol. 1968;31:795-798.

108. Silva PD, Larson KM. Laparoscopic removal of a perforated intrauterine device from the perirectal fat. J Soc Laparosc Surg. 2000;4:159-162.

109. Markovitch O, Klein Z, Gidoni Y, Holzinger M, Beyth Y. Extrauterine mislocated IUD: is surgical removal mandatory? Contraception. 2002;66:105-108.

110. Haimov-Kochman R, Doviner V, Amsalem H, Prus D, Adoni A, Lavy Y. Intraperitoneal levonorgestrel-releasing intrauterine device following uterine perforation: the role of progestins in adhesion formation. Hum Reprod. 2003;18:990-993.

111. Smith DC. Removal of an ectopic IUD through the laparoscope. Am J Obstet Gynecol. 1969;105:285-286.

112. Dunn JS, Zerbe MJ, Bloomquist JL, Ellerkman RM, Bent AE. Ectopic IUD complicating pregnancy. J Reprod Med. 2002;47:57-59.

113. Hopkins MR, Agudelo-Suarez P, El-Nashar SA, Creedon DJ, Rose CH, Famuyide AO. Term pregnancy with intraperitoneal levonorgestrel intrauterine system: a case report and review of the literature. Contraception. 2009;79:323-327.

114. Gill RS, Mok D, Hudson M, Shi X, Birch DW, Karmali S. Laparoscopic removal of an intra-abdominal intrauterine device: case and systematic review. Contraception. 2012;85:15-18.

115. Zakin D, Stern WZ, Rosenblatt R. Complete and partial uterine perforation and embedding following insertion of intrauterine devices. II. Diagnostic methods, prevention and management. Obstet Gynecol Surv. 1981;36:401-417.

116. Turok DK, Gurtcheff SE, Gibson K, Handley E, Simonsen S, Murphy PA. Operative management of intrauterine device complications: a case series report. Contraception. 2010;82:354-357.

117. Margarit LM, Griffiths AN, Vine SJ. Management of levonorgestrelreleasing intrauterine system (LNG-IUS) uterine perforation. J Obstet Gynaecol. 2004;24:586-587.

118. Selo-Ojeme DO, Eking ME, Welch CC. Uterine perforation and laparoscopic retrieval of a levonorgestrel intrauterine system (Mirena). J Obstet Gynaecol. 2003;23:445-446.

119. Elstein M. IUCD liability. BJOG. 1982;89:11-19.

120. Stillwell S, Searle S. Informed consent for IUD fitting. J Fam Plann Reprod Health Care. 2009;35:132-133.

121. Calman $\mathrm{KC}$, Royston GH. Risk language and dialects. $B M J$. 1997;315:939-942. 


\section{Publish your work in this journal}

Open Access Journal of Contraception is an international, peerreviewed, open access, online journal, publishing original research, reports, reviews and commentaries on all areas of contraception. In addition to clinical research, demographics and health-related aspects, the journal welcomes new findings in animal and preclinical studies

relating to understanding the biological mechanisms and practical development of new contraceptive agents. The manuscript management system is completely online and includes a very quick and fair peer-review system. Visit http://www.dovepress.com/testimonials.php to read real quotes from published authors.

Submit your manuscript here: http://www.dovepress.com/open-access-journal-of-contraception-journal 